\title{
Evaluation of a new interrupter device for measuring bronchial responsiveness and the response to bronchodilator in 3 year old children
}

\author{
S.B. Phagoo, N.M. Wilson, M. Silverman
}

\begin{abstract}
Evaluation of a new interrupter device for measuring bronchial responsiveness and the response to bronchodilator in 3 year old children. S.B. Phagoo, N.M. Wilson, M. Silverman. CERS Journals Ltd 1996

ABSTRACT: The interrupter technique for measuring airway resistance is noninvasive and convenient, and therefore ideally suited for the assessment of induced changes in airway calibre in preschool children. The aim of this study was to evaluate a commercially available interrupter device (based on Microlab 4000), which calculates the interrupter resistance (Rint) from pressure and flow following a brief interruption of expiration during quiet breathing.

The repeatability of $R$ int was assessed, and its response to methacholine challenge and the bronchodilator salbutamol were compared with an indirect technique, the fall in transcutaneous oxygen tension $\left(\mathrm{Ptc}_{\mathrm{t}} \mathrm{O}_{2}\right)$, using the sensitivity index (SI, i.e. the change after challenge expressed in multiples of the baseline standard deviation) in 12 wheezy children (aged 3 yrs \pm 2 months).

The mean (SD) baseline value of $R$ int was $0.91(0.20) \mathrm{kPa} \cdot \mathrm{L}^{-1} \cdot \mathrm{s}$. Short-term repeatability and baseline variability were satisfactory for $R$ int (intraclass correlation coefficient $=0.6$; mean intrasubject coefficient of variation $=13 \%$ ). Although 10 of the 12 subjects obtained a significant response using $R$ int at maximal bronchoconstriction (i.e. SI >2), overall, $R$ int was five times less sensitive than $P \mathrm{tc}, \mathrm{O}_{2}$ (geometric mean SI: $R$ int 3 vs $P$ tc,,$\left.O_{2} 16 ; p<0.0001\right)$. Reversal of obstruction with administration of a bronchodilator was clearly demonstrated in almost all subjects: $R$ int after challenge $\left(\right.$ mean \pm sD) $1.25(0.22) \mathrm{kPa}^{-1} \mathrm{~L}^{-1} \cdot \mathrm{s}$; after salbutamol $0.78(0.19) \mathrm{kPa} \cdot \mathrm{L}^{-1} \cdot \mathrm{s} ; \mathbf{p}<0.001$.

In conclusion, the convenient interrupter resistance method appears more promising for detecting bronchodilator responses than induced bronchoconstriction in wheezy preschool children; however, measurement of transcutaneous oxygen tension provides a reliable indirect means of detecting induced airway obstruction in this age-group.
\end{abstract}

Eur Respir J., 1996, 9, 1374-1380.
Dept of Paediatrics and Neonatal Medicine, Royal Postgraduate Medical School, Hammersmith Hospital, London W12 ONN, UK.

Correspondence: M. Silverman

Department of Child Health

Clinical Sciences Building

Leicester Royal Infirmary

PO Box 65

Leicester LE2 7LX

UK

Keywords: Bronchial responsiveness interrupter technique three year olds

Received: June 191995

Accepted after revision April 11996
Very few reliable techniques are available to assess lung function in the young child. As a result, measurement of airway responsiveness in the growing child remains incomplete. The fall in transcutaneous oxygen tension $\left(P \mathrm{tc}, \mathrm{O}_{2}\right)$ has proved to be a reliable, robust method for the measurement of the response to bronchial challenge [1-5], although it is an indirect measure of change in airway calibre, thought to result from increased ventilation-perfusion mismatch [6]. An alteration in breath sounds upon auscultation of the chest has been reported as a measure of response [7, 8], but lacks sensitivity [9]. The forced oscillation technique (FOT), although recommended for preschool children $[10,11]$, has been demonstrated to be less reliable than originally thought after induced bronchoconstriction [9, 12].

The interrupter technique, like forced oscillation, is a noninvasive method of measuring airway resistance and makes few demands on the subject; it is, therefore, ideally suited to this age-group. The technique assumes that immediately following a brief interruption of airflow, alveolar pressure $(P$ alv $)$ will rapidly equilibrate with pressure at the mouth $\left(P_{\mathrm{mo}}\right)$ [13]. The resistance of the airways can then be estimated by calculating the ratio of the pressure change at the mouth to flow at the time of occlusion $[14,15]$. In previous studies, we validated the measurement of interrupter resistance ( $R$ int) for detecting a response to inhaled methacholine in 5 year old asthmatic children and in normal adults $[12,16,17]$. Rint was found to be similar in sensitivity to the FOT in 5 year olds [12]. Although less sensitive when compared to airway resistance (Raw) measured plethysmographically, or total lung resistance using an oesophageal balloon [17], $R$ int was capable of detecting significant increases in resistance in adults. It has also been reported that $R$ int is equally as sensitive as $R$ aw in detecting the airway response to bronchodilator therapy in older children and adults [18, 19], whilst others have applied the technique to infants [20] and the growing child [21].

The aim of the present study was to provide an evaluation of the interrupter technique in a group of 3 year old asthmatic children, using a new, commercially available, handheld interrupter device [19]. Using the device, 
the interrupter resistance of each breathing cycle could be recorded, thus permitting the construction of concentration-response curves after inducing airway obstruction by methacholine challenge. For comparison, measurements of transcutaneous oxygen tension, previously found acceptable in this age-group, were made. Reversal of obstruction with a $\beta$-agonist bronchodilator at the end of the challenge was used to evaluate the potential of the technique for detecting improvement in airway calibre.

\section{Methods}

\section{Subjects}

Twelve children with episodic or persistent wheeze, all within 2 months of their third birthday ( 9 boys and 3 girls) were recruited from an ongoing cohort being studied in the Paediatric Out-patient Department. Bronchodilator and cromoglycate therapy were withheld for at least $12 \mathrm{~h}$ before each study, but topical corticosteroids were taken as usual. Approval was obtained from the Hospital Ethics Committee and parents gave their written consent.

\section{Methacholine challenge}

The challenge test was carried out using a continuous inhalation, tidal breathing method. This method was chosen because the test required only minimal subject co-operation and could, therefore, be applied to young children. Aerosols of methacholine chloride (Sigma Chemicals Ltd, Poole, Dorset, UK) were delivered from a Wright nebulizer producing an output of $0.14 \mathrm{~mL} \cdot \mathrm{min}^{-1}$ (SD $\pm 0.01 \mathrm{~mL} \cdot \mathrm{min}^{-1}$ ) using $8 \mathrm{~L} \cdot \mathrm{min}^{-1}$ of air as the driving gas.

A clip was placed on the nose and the methacholine aerosol was inhaled through a mouthpiece during quiet breathing for $1 \mathrm{~min}$. Methacholine was inhaled at $5 \mathrm{~min}$ intervals, firstly in fourfold increasing concentrations from $0.5 \mathrm{mg} \cdot \mathrm{mL}^{-1}$, and then in twofold increasing concentrations after the $P \mathrm{tc}, \mathrm{O}_{2}$ had fallen by approximately $1 \mathrm{kPa}$ (about 10\%) from the mean baseline value. The challenge was performed using initially large concentration steps of methacholine in order to shorten the duration of the test [2]. The challenge was continued until a $20 \%$ fall in $P \mathrm{tc}, \mathrm{O}_{2}$ had occurred or the maximum concentration of $16 \mathrm{mg} \cdot \mathrm{mL}^{-1}$ had been delivered, whichever occurred soonest. Airway obstruction was relieved at the end of the challenge by nebulized salbutamol $(2.5 \mathrm{mg})$ given via a face mask.

\section{Measurement of response to challenge}

Interrupter resistance. The interrupter device (prototype of Microlab 4000; Micro Medical Ltd, Rochester, Kent, UK) consisted of an interrupting valve and transducer unit connected to a customized, miniature computer [19]. The head of the transducer unit allowed connection to a face mask. The interrupter valve closed in about $5 \mathrm{~ms}$. A screen pneumotachograph placed between the pressure sensor and the interrupter valve was used to measure flow. The unit was calibrated for measurement of pressure by connecting the transducer head directly to a manometer. Flow calibration was achieved by passing a reference flow through the transducer head via a certified flowmeter (Rotameter, Fisher Controls, Croydon, UK). The microcomputer provided instantaneous calculation of results, which could be printed for inspection after each interruption.

The interrupter device could be programmed to interrupt the airflow during tidal expiration at a predetermined flow. A flow rate of $0.2 \mathrm{~L} \cdot \mathrm{s}^{-1}$ was chosen. This corresponded to near maximal tidal expiratory flow in this age-group and produced an optimal $P \operatorname{mo}(t)$ signal. The valve was then held in the closed position for 100 $\mathrm{ms}$, whilst pressure values were recorded at $1 \mathrm{~ms}$ intervals and stored in memory. The valve then reopened and the pressure data were used to calculate Rint automatically. The interruption $P$ mo signal consists of a rapid initial phase followed by a slower secondary phase separated by high frequency oscillations [14] (fig. 1). The algorithm used to calculate Rint from the secondary pressure phase involves a simple, two-point linear regression of the postocclusion signal, which is back-extrapolated to an arbitrary time after valve closure. The time of complete valve closure $(t)$ is taken as occurring at $25 \%$ of the peak value of the first oscillation upstroke [19]. The points are based on the mean pressure values for two 10 ms portions of the data centred on $t+30 \mathrm{~ms}$ (range $t+25$ to $t+35 \mathrm{~ms}$ ) and $t+70 \mathrm{~ms}$ (range $t+65$ to $t+75 \mathrm{~ms}$ ) which are then linearly back-extrapolated to $15 \mathrm{~ms}$ after the valve closure time (i.e.. $t+15 \mathrm{~ms})$. The difference between this calculated pressure $(P$ int $)$ and the preocclusion mouth pressure $(P$ pre $)$ (due to apparatus resistance) is then divided by the preprogrammed value of flow to give the interrupter resistance.

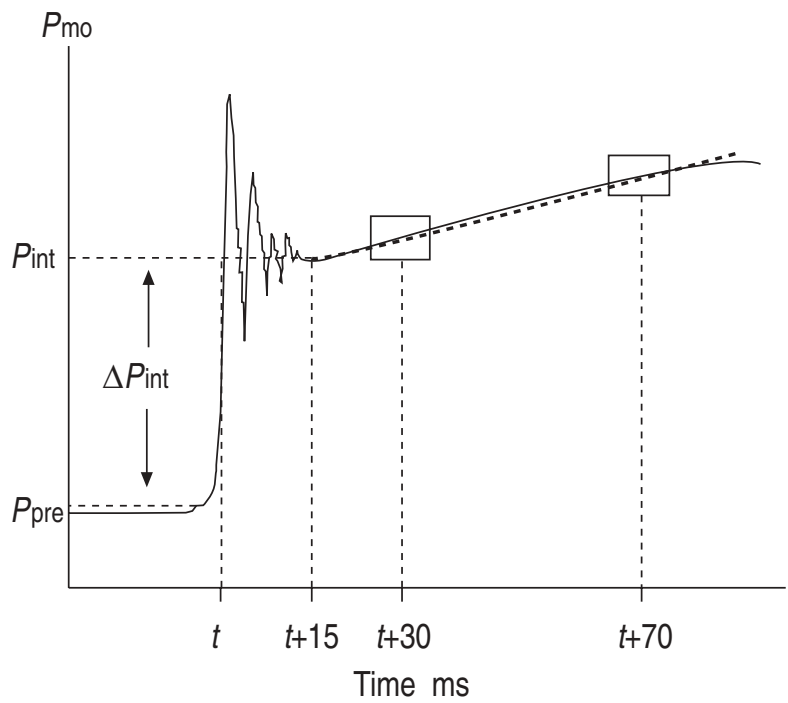

Fig. 1. - Schematic diagram illustrating the calculation of interrupter pressure. The moment of valve closure $(t)$ was taken as the point at which $25 \%$ of the first pressure upstroke had been reached. The mean pressure values for two $10 \mathrm{~ms}$ portions of the data centred on times $t$ $+30 \mathrm{~ms}$ and $t+70 \mathrm{~ms}$ were linearly back-extrapolated to $15 \mathrm{~ms}$ after the valve closure time (i.e. $\mathrm{t}+15 \mathrm{~ms}$ ) to provide the interruption pressure, $(P$ int $)$. The interruption pressure change was calculated as the difference between $P$ int and the preocclusion pressure, $(P$ pre $)$. $P$ mo: mouth pressure. 
During the measurement of $R$ int, the child breathed through a transparent paediatric oronasal face mask with an inflatable air cushion seal. The children were instructed to keep their mouths open but it was not possible to determine whether they were nose or mouth breathing. A series of "practice" attempts were made so that the child could get accustomed to the equipment and the "clicking" noises as the valve closed and reopened. The child's head was supported by the operator and the mask was firmly applied to prevent leakage, as confirmed by inspection of the $P \operatorname{mo}(t)$ waveform (see below). Interrupter measurements were made at the same flow and at the same point on each consecutive breathing cycle.

Data were rejected according to the following criteria: if there was any drift in the baseline; if the extrapolated pressure value was unusually small, indicating mask leakage; or extremely high, indicating either glottic closure, irregular breathing or respiratory muscle activity. Initial readings of $R$ int (which included baseline and the extrapolated mouth pressure) were printed with the $P$ mo $(t)$ curve for inspection; these could be compared with the values without a print-out of the $P \operatorname{mo}(t)$ curves when using the device in continuous operation, which further aided the identification of abnormal data. It was not possible to print out every $P \operatorname{mo}(t)$ curve because of time restrictions after inhaling methacholine.

In order to test the repeatability of $R$ int, three sets of six baseline measurements $(R 1, R 2$ and $R 3)$ were taken with a $15 \mathrm{~s}$ interval between each set. Six measurements were taken after methacholine and bronchodilator administration. The value of $R$ int is given as the mean of the six recordings whenever measured.

Transcutaneous oxygen tension. $P \mathrm{tc}, \mathrm{O}_{2}$ was measured with a skin electrode (Cutan $\mathrm{PO}_{2}$ monitor 820, Kontron Instruments, Switzerland) attached to the chest wall and heated to $44^{\circ} \mathrm{C}$ [1]. The electrode was calibrated before use in air $(20.9 \mathrm{kPa})$. After at least a $20 \mathrm{~min}$ equilibration period to allow the $P \mathrm{tc}, \mathrm{O}_{2}$ to stabilize, baseline values were obtained manually at $1 \mathrm{~min}$ intervals for $8 \mathrm{~min}$. $P \mathrm{tc}, \mathrm{O}_{2}$ values were recorded at precisely $1 \mathrm{~min}$ intervals for 3 min after the end of each nebulization. During measurements, the subject was encouraged to remain as quiet as possible. Coughing, taking big breaths, or vigorous movement may have altered the blood gas readings. The fall in $P \mathrm{tc}, \mathrm{O}_{2}$ occurring $3 \mathrm{~min}$ after each inhalation was used to construct a concentration-response curve.

\section{Expression of results and statistical analysis}

Repeatability of baseline $P$ tc, $\mathrm{O}_{2}$ was assessed using the within-subject coefficient of variation $(\mathrm{CoV})$, the standard deviation of repeat measurements expressed as a percentage of the mean. The repeatability of consecutive sets of $R$ int baselines was calculated using the intraclass correlation (IC) coefficient, a dimensionless measure of repeatability, by dividing the between subject variance by the variance in a one-way analysis of variance (ANOVA) [22]. Measurement sensitivity was expressed as the percentage change from baseline after bronchoconstriction and as a sensitivity index (SI), i.e. the absolute change after challenge in multiples of the baseline standard deviation as described by BuHr et al. [11]. Baseline values and postchallenge or postbronchodilator measurements were compared by paired t-test. Log transformed SI values and percentage changes were analysed using ANOVA and paired t-tests.

\section{Results}

\section{Baseline measurements}

All subjects readily accepted the face mask, adapted quickly to the clicking noises of the valve after a short "practice", and settled down to breathe quietly. Children were not distressed, even after maximally induced bronchoconsriction, while breathing through the interrupter valve. The baseline variability of repeated sets of $R$ int measurements $(R 1-R 3)$ is indicated in table 1 . The intraclass correlation $(\mathrm{IC}=0.6)$ indicated a satisfactory level

Table 1. - Repeatability of baseline interrupter resistance and comparison of variability of Rint and ${\mathrm{Ptc}, \mathrm{O}_{2}}_{2}$ for each 3 year old subject

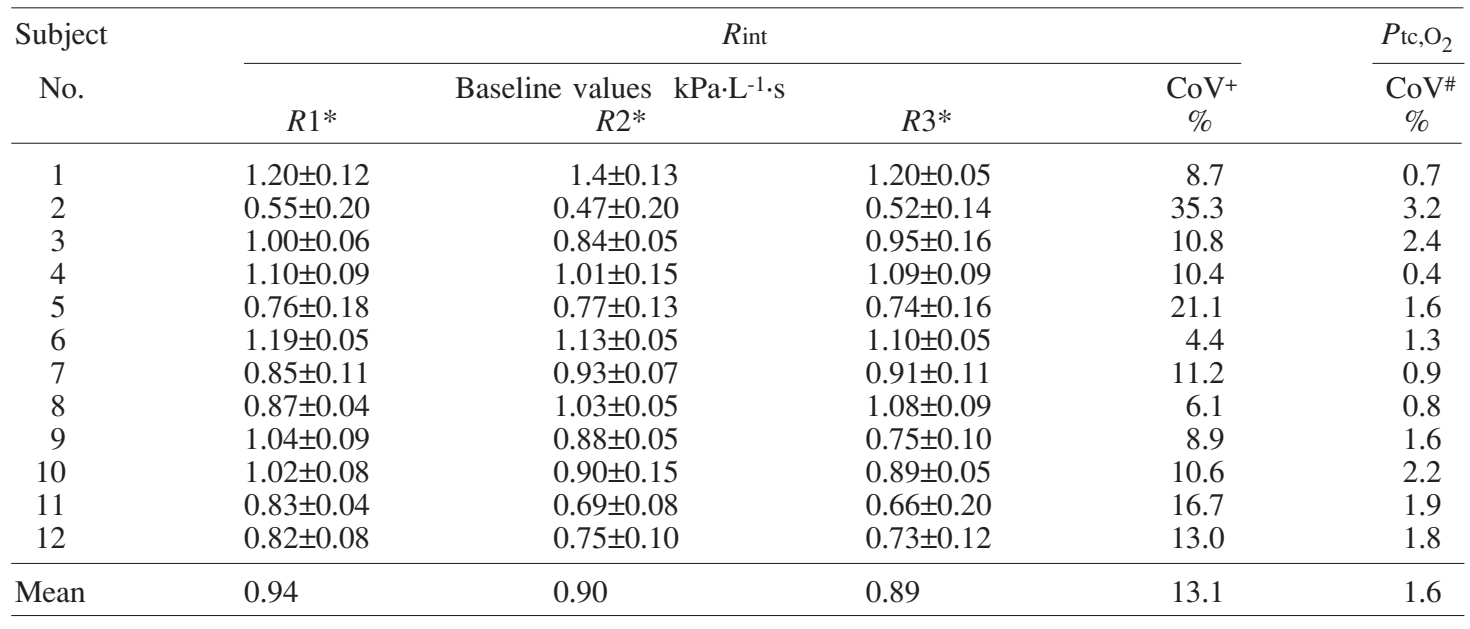

+: CoV based on pooled estimate of 18 measurements; \#: CoV based on pooled estimate of 8 measurements; *: each value is the mean $\pm 1 \mathrm{sD} R$ int of six consecutive measurements. Rint: interrupter resistance; $P_{\mathrm{tc}, \mathrm{O}_{2}}$ : transcutaneous oxygen tension; $\mathrm{CoV}$ : coefficient of variation. 
a)
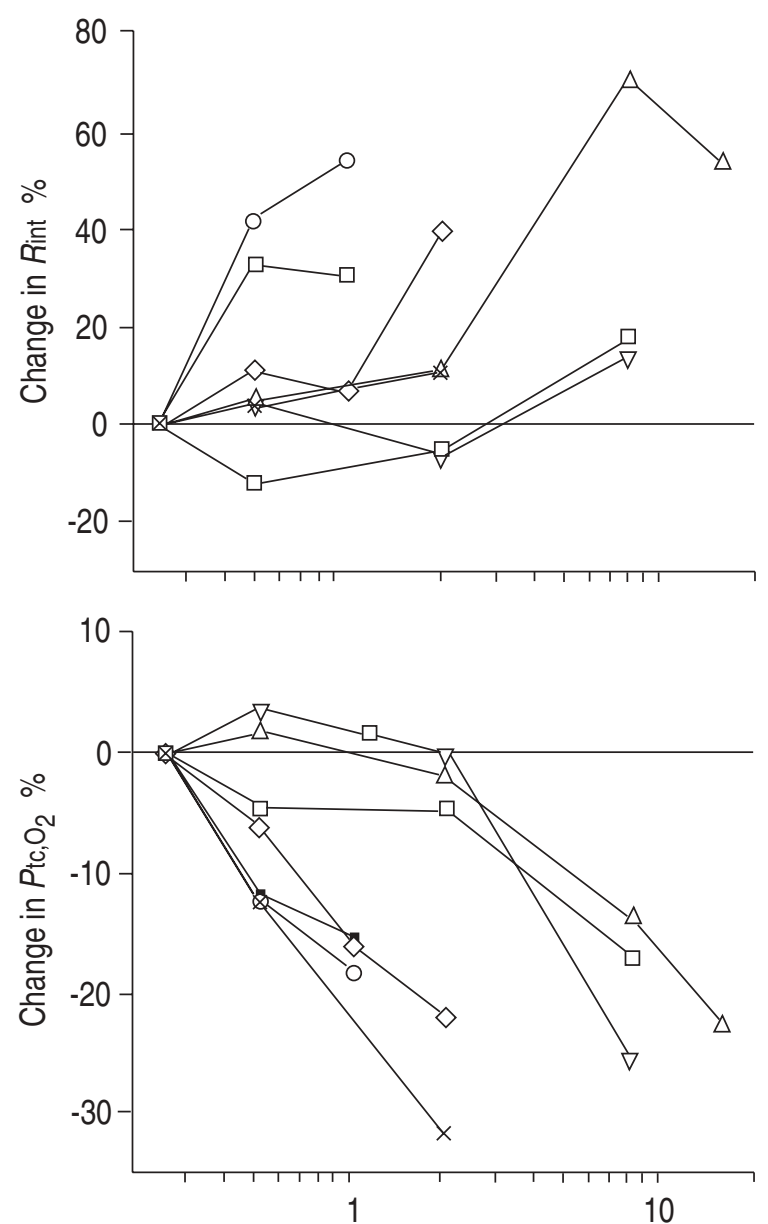

b)

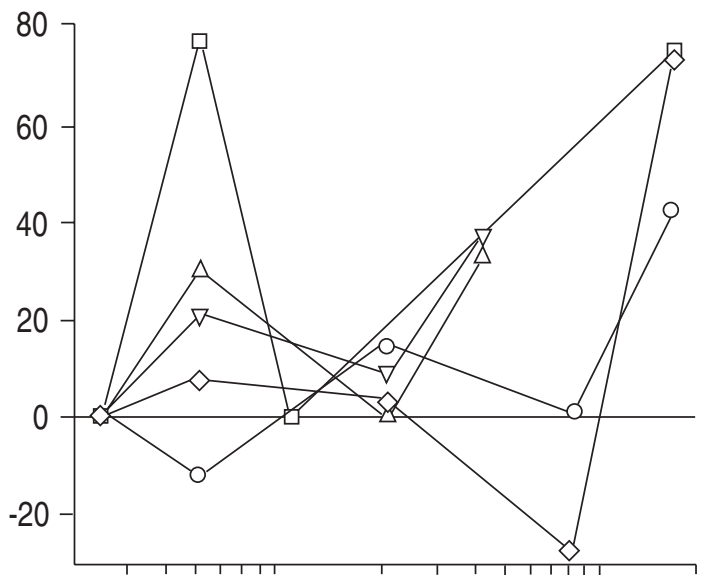

10

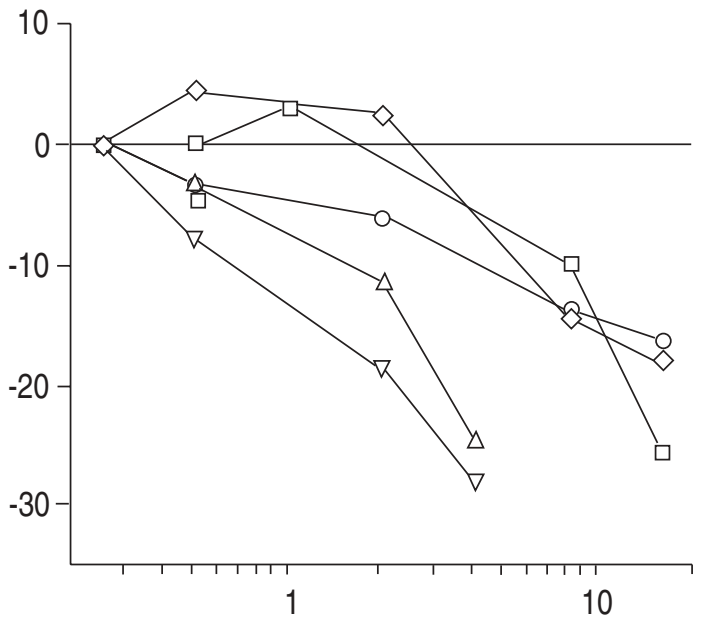

Concentration of methacholine $\mathrm{mg} \cdot \mathrm{mL}^{-1}$

Fig. 2. - Comparison of changes in interrupter resistance ( $R$ int) and transcutaneous oxygen pressure $\left(P_{\mathrm{tc}, \mathrm{O}_{2}}\right)$ in 12 children aged 3 yrs: a) subjects showing a consistent increase in Rint with increasing concentration of inhaled methacholine; b) subjects with inconsistent changes in $R$ int with increasing concentration of inhaled methacholine.

of measurement repeatability. The mean within subject $\mathrm{CoV}$ based on the pooled estimate of all baseline measurements (total of 18 measurements) ranged $4-35 \%$, with a mean of $13 \%$ (table 1 ). In contrast, the mean CoV for $P \mathrm{tc}, \mathrm{O}_{2}$ measurements (based on eight observations) was 10 fold smaller (range $0.4-3.2 \%$, mean $1.6 \%$ ).

\section{Comparison of concentration response curves for Rint and $\mathrm{Ptc}_{\mathrm{tc}} \mathrm{O}_{2}$}

In contrast to the consistent concentration-response relationships for all subjects using $P \mathrm{tc}, \mathrm{O}_{2}$, those for $R$ int were inconsistent in five subjects (fig. 2). For the group as a whole, a significant change $(\mathrm{p}<0.0001)$ in both $R$ int and $P \mathrm{tc}, \mathrm{O}_{2}$ was obtained at maximal bronchoconstriction.

Sensitivity of Rint to detect change in airway calibre during methacholine challenge and following bronchodilation

Following a $\geq 15 \%$ change in $P$ tc, $\mathrm{O}_{2}$ in all subjects after the maximum concentration of methacholine administered, a change in Rint of $\geq 30 \%$ or $\geq 40 \%$ was obtained in 9 and 6 out of 12 subjects, respectively (table 2). The geometric mean SI value for $R$ int was about five times smaller $(\mathrm{p}<0.0001)$ than that obtained for $P \mathrm{tc}, \mathrm{O}_{2}$.

Following bronchodilator, the fall in Rint was significant (i.e. $>2$ SD fall in Rint from mean post-challenge value) in 11 of the 12 subjects (fig. 3, table 2). In the remaining subject (No. 12), the fall in Rint after bronchodilator was comparable in magnitude to the rise in $R$ int induced in the challenge; however, these changes were not significant. The geometric mean SI for the reversal in bronchoconstriction using Rint was 4.9.

\section{Discussion}

In this study, an evaluation of a new hand held interrupter device for assessing the response to changes in airway calibre was performed in 3 year old children. We found that in several subjects it was impossible to detect significant responses to bronchoprovocation despite a clear change in $\mathrm{Ptc}_{\mathrm{tc}} \mathrm{O}_{2}$. However, the interrupter device could be used to detect a reversal in obstruction after administration of salbutamol in almost all subjects, perhaps because the absolute change in resistance was 
Table 2. - Comparison of response to methacholine challenge measured using $R$ int and $P_{\mathrm{tc}, \mathrm{O}_{2}}$ and after reversal of obstruction with salbutamol measured in 12 children aged 3 yrs

\begin{tabular}{|c|c|c|c|c|c|c|c|c|c|c|c|}
\hline \multirow{3}{*}{$\begin{array}{c}\text { Subject } \\
\text { No. }\end{array}$} & \multicolumn{4}{|c|}{${\mathrm{Ptc}, \mathrm{O}_{2}}_{2}$} & \multicolumn{7}{|c|}{$R$ int } \\
\hline & \multirow{2}{*}{$\begin{array}{c}\text { Baseline } \\
\text { Mean } \\
\mathrm{kPa}\end{array}$} & \multicolumn{3}{|c|}{ Max bronchoconstriction } & \multirow{2}{*}{$\begin{array}{c}\text { Baseline } \\
\text { Mean }^{+} \\
\mathrm{kPa} \cdot \mathrm{L}^{-1} \cdot \mathrm{s}\end{array}$} & \multicolumn{3}{|c|}{ Max bronchoconstriction } & \multicolumn{3}{|c|}{ Postsalbutamol } \\
\hline & & $\begin{array}{c}\text { Mean } \\
\mathrm{kPa}\end{array}$ & $\underset{\%}{\text { Change }}$ & SI & & $\begin{array}{c}\text { Mean } \\
\mathrm{kPa} \cdot \mathrm{L}^{-1} \cdot \mathrm{s}\end{array}$ & $\underset{\%}{\text { Change }}$ & SI & $\begin{array}{c}\text { Mean } \\
\mathrm{kPa} \cdot \mathrm{L}^{-1} \cdot \mathrm{s}\end{array}$ & $\underset{\%}{\text { Change* }}$ & SI \\
\hline 1 & 11.3 & 9.6 & -15 & 21.3 & 1.26 & 1.65 & 31 & 3.6 & 0.96 & -72 & 8.3 \\
\hline 2 & 10.3 & 7.7 & -25 & 7.7 & 0.51 & 0.89 & 75 & 2.1 & 0.50 & -78 & 2.2 \\
\hline 3 & 9.9 & 8.1 & -18 & 7.5 & 0.93 & 1.43 & 54 & 5.0 & 0.91 & -57 & 5.3 \\
\hline 4 & 11.4 & 8.6 & -25 & 7.0 & 1.06 & 1.41 & 33 & 3.2 & 0.53 & -166 & 16.0 \\
\hline 5 & 11.1 & 8.6 & -23 & 13.9 & 0.76 & 1.17 & 54 & 2.6 & 0.55 & -113 & 5.3 \\
\hline 6 & 10.7 & 8.0 & -25 & 30.0 & 1.14 & 1.30 & 14 & 3.2 & 1.00 & -30 & 6.8 \\
\hline 7 & 11.9 & 10.0 & -16 & 17.3 & 0.89 & 1.26 & 42 & 3.8 & 0.89 & -42 & 3.7 \\
\hline 8 & 10.1 & 7.9 & -22 & 27.5 & 0.99 & 1.39 & 40 & 6.6 & 1.00 & -39 & 6.4 \\
\hline 9 & 8.9 & 6.4 & -28 & 17.9 & 0.90 & 1.23 & 37 & 4.2 & 0.90 & -37 & 4.1 \\
\hline 10 & 11.4 & 7.8 & -32 & 14.4 & 0.94 & 1.04 & 11 & 1.0 & 0.81 & -28 & 2.7 \\
\hline 11 & 12.0 & 9.9 & -18 & 9.1 & 0.73 & 1.26 & 73 & 4.4 & 0.58 & -117 & 7.0 \\
\hline 12 & 8.9 & 7.4 & -17 & 9.4 & 0.77 & 0.91 & 18 & 1.4 & 0.75 & -21 & 1.6 \\
\hline Mean & 10.7 & 8.3 & -22 & $16.4^{\#}$ & 0.91 & 1.25 & 40 & $3.0^{\#}$ & 0.78 & 67 & $4.9^{\#}$ \\
\hline
\end{tabular}

*: calculated as percentage change from maximum bronchoconstriction value; +: based on pooled estimate of 18 measurements; \#: geometric mean. $P$ tc, $\mathrm{O}_{2}$ : transcutaneous oxygen tension; Rint: interrupter resistance; SI: sensitivity index.

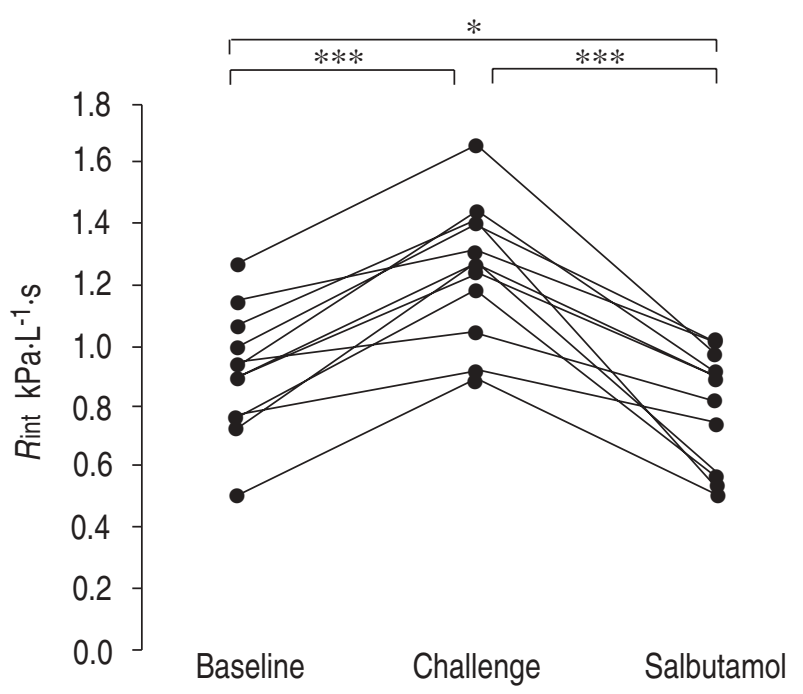

Fig. 3. - Individual values of baseline interrupter resistance, after maximal methacholine-induced bronchoconstriction and $15 \mathrm{~min}$ following reversal with administration of salbutamol in 12 children aged 3 yrs. *: $\mathrm{p}<0.05$; ***: $\mathrm{p}<0.0001$.

greater after bronchodilator, or due to an improvement in the estimation of alveolar pressure itself.

In order to determine the baseline variability of Rint, we measured three consecutive sets of six measurements. Repeatability assessed using the intraclass correlation coefficient was satisfactory [23]. For the group as a whole, the variability assessed with the $\mathrm{CoV}$ in 3 year olds was similar to that obtained in 5 year olds and adults $[12,16$, $17,19]$, and no more variable than for other commonly obtained physiological parameters in children [24]. There are several possible explanations for the poor variability observed in three of the 3 year olds in the present study. $R$ int was measured while the individual breathed through a transparent oronasal mask with the mouth slightly open; it was, however, difficult to determine whether the children were nose or mouth breathing and whether a consistent breathing pattern was maintained between each set of measurements. Spontaneous switching between oral and nasal routes is one possible reason for the variability. For clinical use, Rint methods have to rely upon the collection of $P \operatorname{mo}(t)$ curves during quiet breathing. Inevitably, effects due to respiratory muscle activity [25, 26] and to upper airway compliance [27] can distort the pressure signal. Uncontrollable movement of the tongue or variations in the size of the glottic aperture could all have had a substantial influence on the upper airway geometry and, hence, led to measurement variability. Most of the children could be persuaded to accept a mouthpiece, but many experienced difficulty in maintaining an adequate seal. The design of an appropriate mouthpiece with a flanged edge to prevent leaks and incorporating a noseclip, may reduce the variation of the measurement of $R$ int in 3 year olds.

A source of nonbiological variability may have been introduced from the design of the interrupter device itself. This incorporates a single transducer which is used to measure airflow as a function of recorded pressure prior to interruption and mouth pressure immediately after interruption. Consequently, the device is preprogrammed to activate valve closure using a particular flow (in this case $0.2 \mathrm{~L} \cdot \mathrm{s}^{-1}$ ) and, therefore, the exact flow which coincides with valve closure is unknown. This could potentially cause measurement error.

Currently, there is no fully validated method of assessing the response to bronchial challenge in this age-group. The $P \mathrm{tc}, \mathrm{O}_{2}$ method had been shown to be a robust method and more reliable and sensitive than the advocated FOT in the presence of moderate bronchoconstriction in young asthmatic children [9]. The $P \mathrm{tc}, \mathrm{O}_{2}$ was, therefore, considered to be the most suitable choice for assessing the response to bronchial challenge in this study. In comparison to $R$ int, which is a measurement of airways resistance, the fall in $P \mathrm{tc}, \mathrm{O}_{2}$ after administration of bronchoconstrictor is thought to reflect ventilation/perfusion ratio ( $\left.\mathrm{V}^{\prime} / \mathrm{Q}^{\prime}\right)$ inequality [6]. Although it is known that the primary cause of $\mathrm{V}^{\prime} / \mathrm{Q}^{\prime}$ mismatch after challenge stems from airway 
narrowing, it is not clear whether it is the peripheral or central airways which are responsible. Nevertheless, falls in $P$ tc, $\mathrm{O}_{2}$ and increases in total lung resistance measured using the FOT generally correlate after bronchoconstriction $[1,9]$, and therefore $P \mathrm{tc}, \mathrm{O}_{2}$ can be used to indirectly assess reductions in airways calibre.

The concentration-response curves obtained for $P \mathrm{tc}, \mathrm{O}_{2}$ were more consistent than those obtained using $R$ int; all subjects achieved a significant change in $P \mathrm{tc}, \mathrm{O}_{2}$ from baseline at a concentration prior to the maximum concentration of methacholine administered, as previously demonstrated in 5 year olds after methacholine challenge [12]. It had been expected that $R$ int would be equally as sensitive in 3 year old as in 5 year old children, but the SI values for the $3 \mathrm{yr}$ old group were lower than in the 5 year olds (3 yrs geometric mean (range) 3.0 (1.0-6.6); 5 yrs 4.2 (1.4-11.4)) [12]. Following a $\geq 15 \%$ fall in $P$ tc, $\mathrm{O}_{2}$ in 3 year olds, Rint had changed by a threshold of $>2$ SI in 10 of the 12 subjects. The remaining two subjects obtained a SI index of 1.4 and 1.0. In contrast, the response to bronchoconstrictor measured using $P \mathrm{tc}, \mathrm{O}_{2}$ changed by more than 7 SI in all subjects.

There are several factors which may contribute to the lack of sensitivity of $R$ int in the 3 year olds. Since the interrupter technique relies upon the measurement of mouth pressure to represent alveolar pressure $(P$ alv $)$, the presence of airway obstruction may retard equilibration and lead to underestimation of the latter [28-30]. BATES et al. [14] and LuDwIG et al. [31] reported that in normal, tracheotomized, paralysed anaesthetized, open-chested dogs, the pressure recorded at the trachea is virtually identical to that of $P$ alv after airflow interruption. This implies that $R$ int is effectively a measurement of airway resistance in the open-chest model. After the animals were treated with histamine aerosols, significant regional differences in $P$ alv were noted [31]; however, it was concluded that under these conditions $R$ int continued to be a useful reflection of the flow resistance of the overall airway tree. This has recently been confirmed by SMiтH et al. [32] after methacholine challenge in rabbits.

Based on model studies, BATES et al. [27] estimated that an increase of up to 10 times in airway resistance would still be correctly measured by the interrupter technique if compliance of the upper airways is not excessively high. We have previously shown [16] that in spontaneously breathing adults the prediction of BATES et al. [27] is essentially true, and is in agreement with data reported by others [33] and in other situations in adults [34]. Also, under controlled conditions in the laboratory, Rint was capable of detecting a significant ( $>2$ SI) change in 9 out of 10 asthmatic children aged 5 yrs at a level to change $P$ tc, $\mathrm{O}_{2}$ by $>15 \%$. The prediction of BATES et al. [27], however, cannot be extrapolated to 3 year old children as the approximate initial pressure appears to underestimate the pressure change required to calculate resistance after moderately induced bronchoconstriction. Although we have shown that $R$ int is capable of detecting the bronchial response to methacholine at the maximal concentration administered, responses obtained at submaximal concentrations were unreliable in many of the 3 year old children. This interrupter device cannot, therefore, be advocated for measuring gradual responses to bronchoprovocation in this age-group under these conditions.
The compliant extrathoracic airway which includes the cheeks and floor of the mouth, reduces the change in $P$ mo due to dissipation of pressure after interruption [27, $28]$. Both effects will result in underestimation of true $R$ int. In the present study, support of the most distensible part of the upper airways, the cheeks, was provided by the inflated cuff of the oronasal mask, which projected beyond the centre of the cheeks. The mask itself increased the dead space volume of the interrupter valve by $20-25 \mathrm{~mL}$, introducing another small potential source of error in the measurement [20].

The method of $R$ int calculation involved a linear backextrapolation of two discrete portions of the $P \operatorname{mo}(t)$ curve located in the second half of the trace. This form of analysis is probably most sensitive to traces which have a relatively horizontal or linear second portion. Any concavity with respect to the $\mathrm{x}$ axis will tend to cause an underestimation of $R$ int. In contrast to adults, preschool children have "knee-shaped" curves even under baseline conditions, which become progressively more exaggerated after induced obstruction [12], indicating poor equilibration between $P$ mo and $P$ alv. The analysis of the slow second pressure change by BATEs et al. [27] indicates that in tracheostomized animals with normal lungs the main contribution to this pressure change is stress relaxation of the lung tissues and chest wall [35]. However, in the presence of airway narrowing, a further component of the second pressure change results from gas redistribution between parallel pathways (pendelluft) [31]. Additionally, there may also he continuing respiratory muscle activity (increasing $P$ alv). Therefore, this form of $R$ int analysis of the $P \operatorname{mo}(t)$ curve may not be optimal for this age-group. Values of $P$ mo taken from a later part of the curve may provide better sensitivity but are of unknown physiological significance [17].

The reversal of airflow obstruction after administration of a bronchodilator was clearly detected using $R$ int. In every subject, the value of $R$ int after salbutamol was significantly lower than the baseline value (mean (SD) baseline $0.91(0.20) \mathrm{kPa} \cdot \mathrm{L}^{-1} \cdot \mathrm{s}$; after salbutamol $0.78(0.19)$ $\left.\mathrm{kPa} . \mathrm{L}^{-1} \cdot \mathrm{s} ; \mathrm{p}<0.05\right)$. These results are in agreement with those reported in adults with reversible airways disease [19], in which $R$ int was shown to be as sensitive as body plethysmography in detecting changes in airway resistance following administration of a bronchodilator.

Few other lung function techniques have been applied in 3 year olds. Forced expiratory manoeuvres are effortdependent and restricted to only the most co-operative young child. The determination of Rint calculated from a linear back-extrapolation technique appears promising at least for detecting an improvement in airway calibre; and, hence, may find use in bronchodilator trials in preschool children where few other direct techniques exist. Measurements with a specially designed mouthpiece to reduce baseline variability coupled with maximal upper airways support may improve the sensitivity of $R$ int for challenge testing. Refinements in the $P \operatorname{mo}(t)$ analysis may also be beneficial. The measurement of a fall in $P$ tc, $\mathrm{O}_{2}$, as shown previously, provides a reliable indicator of induced bronchoconstriction.

Acknowledgements: The authors are grateful to the National Asthma Campaign for their support. The interrupter device was kindly provided by Micro Medical Ltd, Rochester, UK. 


\section{References}

1. Wilson NM, Phagoo SB, Silverman M. The use of transcutaneous oxygen tension, arterial oxygen saturation and respiratory resistance to assess the response to inhaled methacholine in asthmatic children and normal adults. Thorax 1991; 46: 433-437.

2. Phagoo SB, Wilson NM, Silverman M. Repeatability of methacholine challenge in asthmatic children measured by change in transcutaneous oxygen tension. Thorax 1992; 47: 804-808.

3. Wilson NM, Phagoo SB, Silverman M. Atopy, bronchial responsiveness and symptoms in wheezy 3 year olds. Arch Dis Child 1992; 67: 492-495.

4. Mochizuki H, Mitsuhashi M, Tokuyama K, Tajima K, Morikawa A, Kuroume T. A new method of estimating bronchial hyperresponsiveness in younger children with asthma. Ann Allergy 1988; 60: 103-106.

5. Mochizuki H, Mitsuhashi M, Tokuyama K, Tajima K, Morikawa A, Kuroume T. A new method of estimating bronchial hyperresponsiveness in younger children. Ann Allergy 1985; 55: 162-166.

6. Hedlin G, Freyschuss V, Hedenstierna G. Histamine-induced asthma in children: effects on the ventilation-perfusion relationship. Clin Physiol 1985; 5: 19-34.

7. Avital A, Bar-Yishay E, Springer C, Godfrey S. Bronchial provocation tests in young children using tracheal auscultation. J Pediatr 1988; 112: 591-594.

8. Sanchez I, Avital A, Wong I, Tal A, Pasterkamp H. Acoustic $v s$ spirometric assessment of bronchial responsiveness to methacholine in children. Pediatr Pulmonol 1993; 15: 28-35.

9. Wilson NM, Bridge P, Phagoo SB, Silverman M. The measurement of methacholine responsiveness in 5 year old children: three methods compared. Eur Respir $J$ 1995; 8: 364-370.

10. Duiverman EJ, Neijens HJ, Van Strik R, Van Der Snee-Van Smaalen M, Kerrebijn KF. Bronchial responsiveness in asthmatic children aged 3 to 8 years measured by forced pseudorandom noise oscillometry. Bull Eur Physiopathol Respir 1986; 22: 27-34.

11. Buhr W, Jorres R, Berdel D, Landser FJ. Correspondence between forced oscillation over body plethysmography during bronchoprovocation with carbachol in children. Pediatr Pulmonol 1990; 8: 280-288.

12. Phagoo SB, Wilson NM, Silverman M. Evaluation of the interrupter technique for measurement of change in airway resistance in 5 year old asthmatic children. Pediatr Pulmonol 1995; 20: 387-395.

13. Von Neergaard K, Wirz K. Die messung des stromungswiderstandes in den atem-wegen des menschen, insbesondere bei asthma und emphysema. Z Klin Med 1927; 105: 51-82.

14. Bates JHT, Baconnier P, Milic-Emili J. A theoretical analysis of interrupter technique for measuring respiratory mechanics. J Appl Physiol 1988; 64: 2204-2214.

15. Jackson AC, Milhorn HT Jr, Norman JR. A re-evaluation of the interrupter technique for airway resistance measurement. J Appl Physiol 1974; 36: 264-268.

16. Phagoo SB, Watson RA, Pride NB, Silverman M. Accuracy and sensitivity of the interrupter technique for measuring the response to bronchial challenge. Eur Respir $J$ 1993: 6; 996-1003.

17. Phagoo SB, Watson RA, Silverman M, Pride NB. Comparison of four methods of assessing airflow resistance before and after induced airway narrowing in normal subjects. J Appl Physiol 1995; 79: 518-525.

18. Carter ER, Stecenko AA, Pollock BH, Jaeger MJ. Evaluation of the interrupter technique for the use of assessing airway obstruction in children. Pediatr Pulmonol 1994; 17: 211-217.

19. Chowienczyk PJ, Lawson PC, Lane S, et al. A flow interruption device for the measurement of airway resistance. Eur Respir J 1991; 4: 623-628.

20. Sly PD, Bates JHT. Computer analysis of physical factors effecting the use of the interrupter technique in infants. Pediatr Pulmonol 1988; 4: 219-224.

21. Lanteri CJ, Sly PD. Changes in respiratory mechanics with age. J Appl Physiol 1993; 74: 369-378.

22. Fleiss JL. The design and analysis of clinical experiments. New York, John Wiley \& Sons, 1986; pp. 1-14.

23. Chinn S. Repeatability and method comparison. Thorax 1991; 46: 454-456.

24. Silverman M. Asthma in childhood. Cambridge, Current Medical Literature Ltd University Press, 1985.

25. Shee CD, Ploy-Song-Sang Y, Milic-Emili J. Decay of inspiratory muscle pressure during expiration in conscious humans. J Appl Physiol 1985; 58: 1859-1865.

26. Gottfried SB, Higgs BD, Rossi A, et al. Interrupter technique for measurement of respiratory mechanics in anaesthetised humans. J Appl Physiol 1985; 59: 647652.

27. Bates JHT, Sly PD, Kochi T, Martin JG. The effect of a proximal compliance on interrupter measurements of resistance. Respir Physiol 1987; 70: 301-312.

28. Jaeger MJ. Effect of the cheeks and the compliance of alveolar gas on the measurement of respiratory variables. Respir Physiol 1982; 47: 325-340.

29. Fichter J, Wierich W, Hartung W. Resistance measurements in normal and obstructed excised human lungs by means of the interrupter method. Respiration 1989; 56; 34-42.

30. Clements JA, Sharp JT, Johnson RP, Elam JO. Estimation of pulmonary resistance by repetitive interruption of airflow. J Clin Invest 1959; 38: 1262-1270.

31. Ludwig MS, Romero PV, Sly PD, Fredberg JJ, Bates JHT. Interpretation of interrupter resistance after histamine-induced constriction in the dog. J Appl Physiol 1990; 68: 1651-1656.

32. Smith PG, Falahat A, Carlow WA. Measurement of interrupter resistance in rabbits exposed to methacoline. $J$ Appl Physiol 1992; 72: 2454-2457.

33. Liistro G, Stanescu D, Rodenstein D, Veriter C. Reassessment of the interruption technique for measuring flow resistance in humans. J Appl Physiol 1991; 67: 933937.

34. Auler JOC, Zin WA, Caldeira MPR. Pre- and postoperative inspiratory mechanics in ischemic and valvular heart disease. Chest 1987; 92: 984-990.

35. Bates JHT, Brown KA, Kochi T. Respiratory mechanics in the normal dog determined by expiratory flow interruption. J Appl Physiol 1989; 67: 2276-2285. 